www.mjn.mosuljournals.com

\title{
Assessment of Nursing Care through Intravenous Solution Therapy among Children
}

Article information

Article history:

Received April 8, 2018

Accepted January 20, 2019

Available online August 21, 2018

DOI: 10.33899/mjn.2018.162886 @2020, College of Nursing, University of Mosul. Creative Commons Attribution 4.0 International License https://mjn.mosuljournals.com/article_168249.html

Rifaie Yaseen Hameed ${ }^{1}$

Abdulkhaliq Shakir Yousif ${ }^{2}$

\section{$\underline{\text { Abstract }}$}

Intravenous (IV) solution is a scarce human resource and ensuring its safety and clinical effectiveness requires investment - both human and financial. IV solution therapy is an essential part of patient care. When used correctly, it saves life and improves health. The nurse has an important and effective role in implementation and monitoring of care while IV solution infusion. Methods and Materials: This descriptive study was carried out in internal medicine wards and emergency departments in Ibn-AL-Atheer teaching hospital, Ibn-Sina teaching hospital and AL-Khansa'a teaching hospital in Mousl city for the period from $15^{\text {th }}$ October / 2012 to $10^{\text {th }}$ September / 2013 to assess the nursing care throughout procedure of IV solution infusion therapy for children. The sample of the study were convenience composed of (104) nurses while performing intravenous solution infusion in the above hospitals' wards. A special observational tool was prepared utilizing available related literatures . Content Validity of the tool was done through opinions of a panel of (24) experts, while the reliability of tool was done through a pilot study that were $\mathrm{r}_{(\text {Pre) }}=0.77, \mathrm{r}_{\text {(Intra) }}=0.71$ , $r_{\text {(Post) }}=0.78$, and $r_{\text {(Total) }}=0.74$. Results: The acceptable levels of the three stages of procedure as a results of the study were as; Pre-procedure $=98.4 \%$, Intra-procedure $=70.6 \%$ and Post-procedure $=52.6 \%$. Conclusion: The study concluded negligence in some activities are dangerous and can be fatal, heedlessness in case the solution is suitable to be infused or not, and heedlessness or ignorance of sterilization and disinfection. The study recommended that the nurses working in Intravenous solution infusion must be highly qualified and efficient in

\footnotetext{
${ }^{1}$ Assistant Professor / PhD in Community Health Nursing / Technical Institute of Mosul / Nursing Department. e-mail; rifaie1960@ rocketmail.com Mobile; 07701663159

${ }^{2}$ Post Graduate Student / Mosul University / College of Nursing.
} 


\section{Mosul Journal of Nursing, Vol. 6, No. 2, 2018 ( 89-99 )}

regard to IV therapy. Standardized guidelines in respect to sterilization and disinfection throughout each procedure.

Key words: assessment, nursing care, intravenous solution therapy, children.

\section{Introduction;}

Intravenous (IV) simply means "within a vein" IV therapy is a treatment that infuses fluids, medications, blood, or blood products into a vein for treatment of a patient. It permits accurate dosing and a swift effect of the substance infused. IV therapy is used to administer fluids, drugs, and nutrients when a patient cannot take these items orally. The rapid effect of fluids delivered directly into the bloodstream is necessary during emergencies or other critical-care situations in which medications are needed. However, the results can be fatal if the wrong medication or dosage is given [1]. Administration of IV solution to children is common practice in a hospital setting. Children receive IV solution for a variety of reasons, and with the development of accurate modern pumps, delivery rates of these solutions can be controlled and are perceived to be safe. However, serious morbidity and mortality in previously healthy children associated with the administration of IV solutions has been reported [2,3]. So, an order for IV therapy is made by the physician. Various other health care employees are responsible for the procedures surrounding initiation, administration, and maintenance of the IV therapy that has been ordered [1].

Intravenous solution therapy is a major and serious procedure in daily hospital work - that all stages of it has some risks the nurse plays a vital role throughout that, therefore highly qualified nursing staff is needed to be aware of this procedure. The possible complications are "phlebitis, infiltration, infection, allergic reactions, circulatory overload and air embolism". The present study aim is to assess the nursing care through intravenous solution therapy among children in Mosul City.

\section{Methodology;}

A descriptive study design has been adopted throughout the period from $15^{\text {th }}$ of October 2012 to $10^{\text {th }}$ of September 2013. Data were collected from three hospitals in Mosul city (Ibn -AL- Atheer, Ibn- Sina and AL-Khansa'a Teaching Hospitals). A convenience sample of (104) nurses working in pediatrics emergency departments and pediatrics wards in the three hospitals has been included.

After reviewing many previous related literatures, an observational tool was developed to measure nurses' practice throughout the intravenous infusion procedure. It composed of two parts: Part I; related to demographic characteristics of the nurse as Age, Gender, Educational qualifications, Tenure (years of work), Workplace inside the hospital, The hospital that the nurse working in , and Enrollment in Training Sessions. Part II; composed of Procedure related-items consist of three categories or stages: Preprocedure (27) items, Intra- procedure (34) items, Post- procedure (13) items. Each item has four options: Never $=0$; Sometimes $=1 ;$ Often $=2$; Always $=3$. Mean of score depended as an acceptable level was $(\geq 1.5)$. Content validity of the tool was determined by presenting it to a panel of (24) experts, while the researchers selected (10) nurses randomly from IbnAl-Atheer teaching hospital - outside the study sample - to identify the reliability of the tool and by using Spearman-Brown method of split half technique, the reliability coefficient of the total tool and of its' categories were as; Pre- procedure $(\mathrm{r}=0.77)$, Intra- procedure $(\mathrm{r}=0.71)$, Postprocedure $(\mathrm{r}=0.78)$ and Total $(\mathrm{r}=0.74)$. Data were collected through indirect observational method depending on the procedure related - items of the study instrument while the nurse carrying out the procedure. Each nurse had observed for three times of procedure. Each activity pinpointed in respect to the options of each item, then calculated the total scores of the 
Mosul Journal of Nursing, Vol. 6, No. 2, 2018 ( 89-99 )

options. Mean and Standard Deviation

were used as descriptive statistic.

\section{Results;}

Table (1): Demographic Characteristics of the Study Sample :

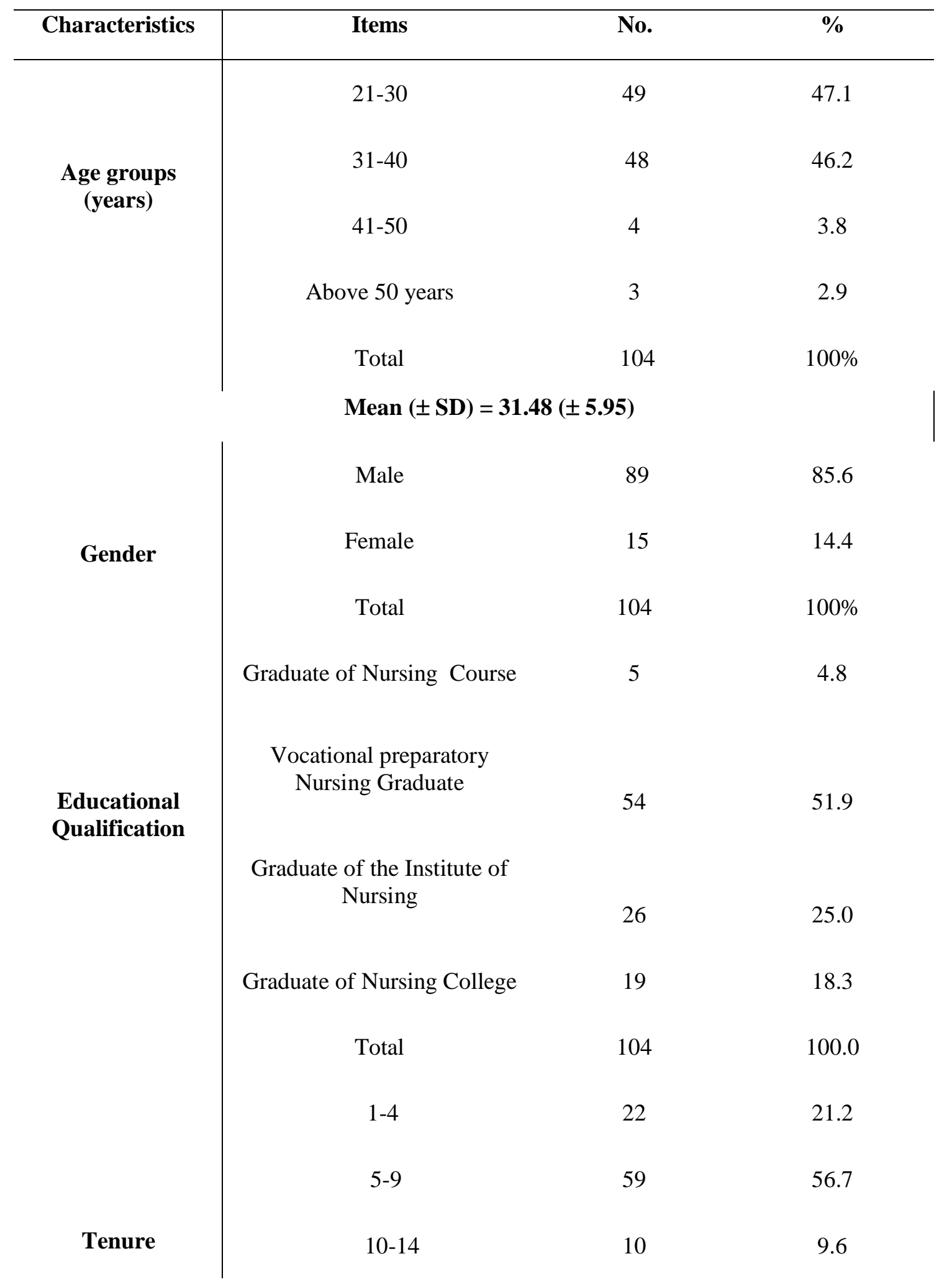


Mosul Journal of Nursing, Vol. 6, No. 2, 2018 ( 89-99 )

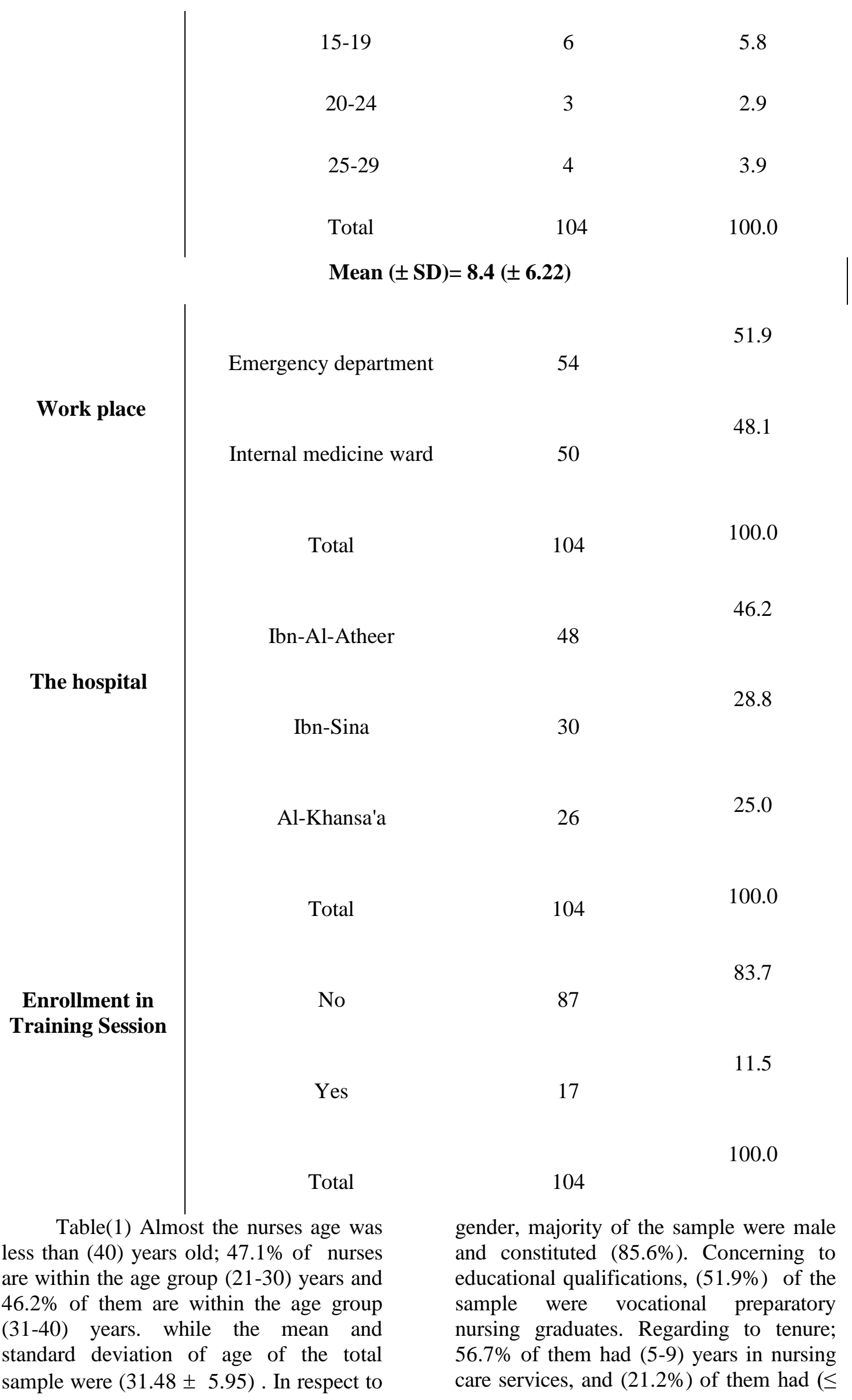




\section{Mosul Journal of Nursing, Vol. 6, No. 2, 2018 ( 89-99 )}

4) years of service period in nursing work, whereas, the mean and standard deviation of tenure of the total sample were $(8.4 \pm$ 6.22) years. Regarding to the work place, the study subject was nearly equally distributed in the two places of work inside the hospitals. In respect to hospital,
(46.2\%) of study subjects were working in Ibn-AL-Atheer teaching hospital and the remaining were distributed somewhat equally. Most members of the sample (83.7\%) had not participated in previous training sessions during their work period

Table (2): Classification of Acceptable Level of Pre- Procedure Activities of Intravenous Solution Therapy by (Mean of score + SD) .

\begin{tabular}{|c|c|c|c|c|}
\hline No & ACTIVITES & Mean & SD & Level \\
\hline A1 & $\begin{array}{l}\text { Assure the correct patient before intravenous solution } \\
\text { administration. }\end{array}$ & 2.9712 & .16818 & acceptable \\
\hline A2 & $\begin{array}{l}\text { Clarify what will be done to the patient and answer } \\
\text { questions of the patient and his her family. }\end{array}$ & 2.3269 & .78136 & acceptable \\
\hline A3 & Wash hands. & 2.4808 & .85877 & acceptable \\
\hline A4 & Wear uniform. & 2.9135 & .50455 & acceptable \\
\hline A5 & Check Temperature. & 2.5192 & .69646 & acceptable \\
\hline A6 & Check Pulse. & .4615 & .81160 & unacceptable \\
\hline A7 & Check respiration. & .1154 & .54519 & unacceptable \\
\hline A8 & Measure the weight of the child. & 2.6827 & .59552 & acceptable \\
\hline A9 & Put the patient in a comfortable position. & 2.6923 & .52282 & acceptable \\
\hline A10 & Wear medical gloves. & 2.3365 & .86586 & acceptable \\
\hline A11 & $\begin{array}{l}\text { Prepare cannula (make sure the size of the cannula by the } \\
\text { veins of the patient). }\end{array}$ & 2.9904 & .09806 & acceptable \\
\hline A12 & Prepare cotton (Swab). & 2.8558 & .51044 & acceptable \\
\hline A13 & Prepare disinfectant solution. & 2.4808 & .88109 & acceptable \\
\hline A14 & Prepare tournique. & 2.9327 & .31972 & acceptable \\
\hline A15 & Prepare adhesive tape (Plaster). & 2.7981 & .50971 & acceptable \\
\hline A16 & $\begin{array}{l}\text { Prepare the site of insertion the cannula preferring the } \\
\text { veins of forearm and hand. }\end{array}$ & 2.9615 & .19324 & acceptable \\
\hline A17 & Tie up the tournique to feel the vein. & 2.9615 & .30918 & acceptable \\
\hline
\end{tabular}




\section{Mosul Journal of Nursing, Vol. 6, No. 2, 2018 ( 89-99 )}

A18 Sterilize the insertion site of cannula by using the disinfectant solution by circular movement from centre outside and wait to dry .

A19 Tighten the skin around the insertion site to make the vein obvious or tangible.

A20 Insert cannula in the vein.

A21 Ascertion from enterance of cannula in correct position by seeing blood in it.

A22 Remove tournique.

A23 Press over a vein by a finger (over the top of the cannula) to prevent bleeding.

A24 Remove the trocar of the tournique and throw it out.

A25 Fix the cannula with adhesion tape.

A26 Administer two cc of normal saline to check the cannula.

A27 Observe the insertion site of cannula.
$.4135 \quad 93071 \quad$ unacceptable

$2.9038 \quad .32737 \quad$ acceptable

$2.2885 \quad 69216 \quad$ acceptable

$2.9038 \quad 32737 \quad$ acceptable

$2.9904 \quad 09806 \quad$ acceptable

$2.7692 \quad .56139 \quad$ acceptable

$2.0769 \quad 66380 \quad$ acceptable

$2.9904 \quad 09806 \quad$ acceptable

$1.8173 \quad 93232 \quad$ acceptable

$2.8558 \quad .42764 \quad$ acceptable

Table (2) shows that the acceptable level of performance are in Activities no. $(1,2.3,4,5,8,9,10,11,12,13,14,15,16,17,19,20,21,22,23,24,25,26,27)$.

Tables (3): Classification of Acceptable Level of Intra- Procedure Activities of Intravenous Solution Therapy by (Mean of score + SD) .

\begin{tabular}{|c|c|c|c|c|}
\hline No & ACTIVITES & Mean & SD & Level \\
\hline B1 & Assure the type of intravenous solution before administering. & 2.4808 & .69646 & acceptable \\
\hline B2 & Ascertain from the expire date of solution and that the bottle is locked well. & .0962 & .49304 & unacceptable \\
\hline B3 & $\begin{array}{l}\text { Be sure that there are no bubbles and precipitates in the bottle, also from it's } \\
\text { temperature before administrating. }\end{array}$ & .6731 & 1.08335 & unacceptable \\
\hline B4 & Clean the rubber piece at the os of the bottle before inserting the tube. & .3750 & .90508 & unacceptable \\
\hline B5 & Hang the bottle at height of one meter over the heart level. & 2.9423 & .41400 & acceptable \\
\hline B6 & Be sure that there is no air bubble in the tube before connecting with cannula. & 3.0000 & .00000 & acceptable \\
\hline B7 & Calculate flow rate. & 1.0096 & 1.22669 & unacceptable \\
\hline B8 & $\begin{array}{l}\text { Instruct the accompanying person about the dangers of re-organize the flow } \\
\text { rate. }\end{array}$ & 2.1635 & 69827 & acceptable \\
\hline B9 & Document time of administration. & .0673 & .42414 & unacceptable \\
\hline
\end{tabular}




\section{Mosul Journal of Nursing, Vol. 6, No. 2, 2018 ( 89-99 )}

B10 Reassure the patient while administration.

B11 Observe site of cannula insertion.

B12 Don't puncture the bottle or pressure on it to faster administration.

B13 Observe the solution level inside the bottle continuously.

B14 Don't leave the administration tube open while lifting it from the patient.

B15 Hand washing.

B16 Change cannula in case of pain or edema in it's site.

B17 Don't lift the patient to a level that his/her heart is over the solution level.

B18 Check temperature continuously during administration.

B19 Check pulse continuously during administration.

B20 Check respiration continuously during administration.

B21 Stop administration in case of occurrence of any complication.

B22 Inform physician in case of elevated patient's temperature.

B23 Inform physician in case of pain sensation in cannula site.

B24 Inform physician in case of inflammation of vein.

B25 Inform physician in case of thrombus.

B26 Inform physician in case of cyanosis.

B27 Inform physician in case of tachycardia.

B28 Inform physician in case of allergy.

B29 Observe the level of conscious of the patient through administration.

B30 Cannula must be changed if it is blocked, be out of the vein, also it must be changed after three days regardless if it is blocked or well.

B31 Administration line tube must be changed with each bottle used.

B32 Block administration line tube before the solution administration is terminated completely.

B33 After completing administration withdraw the administration line tube and close cannula for it can be used later.
$2.7212 \quad .63025$ acceptable

$2.7596 \quad .59927 \quad$ acceptable

$.7692 \quad 1.09926$ unacceptable

$2.8173 \quad .51698 \quad$ acceptable

$.3462 \quad .79768$ unacceptable

$2.6538 \quad 65016 \quad$ acceptable

$2.9808 \quad 19612 \quad$ acceptable

$2.2308 \quad 79110 \quad$ acceptable

$1.9519 .75530 \quad$ acceptable

$.3173 \quad .72760 \quad$ unacceptable

$.1058 \quad 48106$ unacceptable

$2.9135 \quad .50455 \quad$ acceptable

$2.7788 \quad 52058 \quad$ acceptable

$3.0000 \quad 00000$ acceptable

$3.0000 \quad 00000$ acceptable

$2.9135 \quad 39685$ acceptable

$2.5673 \quad 66485$ acceptable

$\begin{array}{lll}1.5673 & 1.16389 & \text { acceptable }\end{array}$

$2.9519 \quad 35197 \quad$ acceptable

$1.9135 \quad 81384$ acceptable

$3.0000 \quad 00000$ acceptable

$.1250 \quad .51554$ unacceptable

$2.2500 \quad 79745 \quad$ acceptable

$3.0000 \quad 00000$ acceptable 


\section{Mosul Journal of Nursing, Vol. 6, No. 2, 2018 ( 89-99 )}

\begin{tabular}{ll|lll} 
B34 Check cannula continuously in case of using for more than one time and take & 2.6731 & .58197 & acceptable
\end{tabular} care of it.

Table (3) shows that the acceptable levels of intra- procedure items are $(1,5,6,8,10,11,13,15,16,17,18,21,22,23,24,25,26,27,28,29,30,32,33,34)$.

Table (4): Classification of Acceptable Level of Post- Procedure Items of Intravenous Solution Therapy by (Mean of score + SD) .

\begin{tabular}{|c|c|c|c|c|}
\hline No & ACTIVITES & Mean & SD & Level \\
\hline $\mathrm{C} 1$ & $\begin{array}{l}\text { Ensure that the patient received sufficient quantity of solution } \\
\text { prescribed by the doctor according to time. }\end{array}$ & 2.9904 & .09806 & acceptable \\
\hline $\mathrm{C} 2$ & Document date, period of time the procedure lasted. & .0481 & .29162 & unacceptable \\
\hline $\mathrm{C} 3$ & Document type of infusion administratered. & 2.9519 & .35197 & acceptable \\
\hline $\mathrm{C} 4$ & Document size and insertion site of cannula. & .0385 & .30918 & unacceptable \\
\hline C5 & Document any problem happened during administration. & .4904 & .83602 & unacceptable \\
\hline C6 & Check temperature after complete administration. & 1.4038 & .79463 & unacceptable \\
\hline $\mathrm{C} 7$ & Check Pulse after complete administration. & .1635 & .44308 & unacceptable \\
\hline $\mathrm{C} 8$ & Check respiration after complete administration. & .0000 & .00000 & unacceptable \\
\hline C9 & $\begin{array}{l}\text { Don't leave any syringe or used instrument at side of the patient } \\
\text { unit after completing the procedure. }\end{array}$ & 2.4519 & .65181 & acceptable \\
\hline $\mathrm{C} 10$ & $\begin{array}{l}\text { Throw out the emptied bottle and other equipments used in a } \\
\text { suitable place after completing the procedure. }\end{array}$ & 2.9519 & .21496 & acceptable \\
\hline $\mathrm{C} 11$ & $\begin{array}{l}\text { Observe the patient continuously after the procedure for ( } 30) \\
\text { minutes later. }\end{array}$ & 2.1635 & .81384 & acceptable \\
\hline $\mathrm{C} 12$ & $\begin{array}{l}\text { Remove cannula and disinfect it's site and provide slight pressure } \\
\text { till the blood ceased. }\end{array}$ & 2.9904 & .09806 & acceptable \\
\hline $\mathrm{C} 13$ & Ascertain of absence of accumulation of fluid or redness in the & 2.9423 & .23429 & acceptable \\
\hline
\end{tabular}

Table (4) depicts that the acceptable level as post-procedure through intravenous solution therapy were for items $(1,3,9,10,11,12,13)$.

\section{Discussion;}

The 'practice of nursing' means the performance of services for compensation in the provision of diagnosis and treatment of human responses to health and illness. Professional nursing practice encompass the full scope of nursing practice and includes all its specialties and consists of application of nursing theory to the development, implementation, and evaluation plans of nursing care for individuals, families, and communities. Professional nursing practice requires 


\section{Mosul Journal of Nursing, Vol. 6, No. 2, 2018 ( 89-99 )}

substantial knowledge of nursing theory and related scientific, behavioral, and humanistic disciplines [4].

Almost the study sample were less than (40) years of age. This is due to two reasons; firstly, the previous economic blockade (1990-2003) the country suffered from compelled large number of employees to leave job, so the nursing vocational schools shard in solving the huge shortage in nursing staff, therefore, all the graduate persons from those schools were around this age group. Secondly, medical specialties inclusively nursing suffered from personnel shortage, so, the government obligates to employee them, therefore, many bachelor students try to attend these professions, hence their ages were youth to early middle ages. Middle east countries especially Arabian communities submit to special values, traditions and beliefs which impose females to be far away as possible as from nursing, so, males constitutes the highest percentage among our sample. As mentioned previously, the vocational nursing schools shared in solving nursing shortage problem, while large percentage of those graduates followed up their education in nursing institute, hence, if adding the percentages of those two groups, it was found that it was more than three-quarters of the sample. Their tenure (years of experience) in nursing field were appropriately in congruity with their ages. Almost the sample due their work overload did not share in any training sessions.

In order to achieve the study objective the researchers tended to assess the nurses' practices during the whole procedure on three stages; pre, intra, and post procedure (Tables; 2-4). The acceptable levels (over than $50 \%$ ) of the three stages were; pre $=$ $98.4 \%$, intra $=70.6 \%$, and post $=52.6 \%$. The most important items that were unaccepted (less than 50\%) in performance can be categorized into four aspects;

Firstly, checking and monitoring some of the vital signs (pulse and respiration) accompanied with calculating of flow rate while fluid administration, this can be fatal, for if speed of flow rate was as rapid as the child need, this logically manifested by tachycardia and dyspnea due to sharp increase in fluids in the body (which must be calculated appropriately) and if it not treat as emergency case as fast as possible, it can affect severely on many vital organs as heart, kidney and so on.

Secondly, ascertain from expire date of fluid administered and any bubbles or precipitates in the bottle in addition to check it's temperature. The early signs of expire date of the fluid are presence of bubbles in fluid while shaking or presence of precipitates in it. If these or one of them is present, the fluid is unsafe to be administered to the human, for, anyone can't predict or be certain from the chemical alterations of fluid or the chemical interactions that can be happened inside the body after administration.

Thirdly, disinfection and sterilization techniques followed during this procedure, as disinfect the insertion site of cannula, disinfect the bottle os, puncture the bottle highest than fluid, and changing the administration line at each bottle administered, all these were unacceptable practices among the study sample which can led to contamination of the fluid. There is growing concern over hospital acquired infection, bacteria and viruses can be carried from person to person on the surface of any medical equipment unless it is decontaminated between use. Sterilization and disinfection reduce the risks of cross infection (the process by which microbes are passed from one infected person to cause infection in another) [5]. Disinfection and 'coldsterilization' solutions destroy many microorganisms (bacteria, viruses, fungi) but do not destroy bacterial spores. Disinfection does not replace autoclave sterilization. Disinfectants should be used on hard surfaces (trays, countertop...) and reusable, non-autoclaveable tools, such as, plastic calipers, before and after each procedure. Product usage instruments vary and some may not be suitable for all surfaces or applications [6]. Sterilization is the process of killing all microorganisms 


\section{Mosul Journal of Nursing, Vol. 6, No. 2, 2018 ( 89-99 )}

including bacteria, bacterial spores, fungi and viruses. Improper sterilization can result in the spread of infectious bacteria and blood borne viruses such as Hepatitis and Human Immunodeficiency Virus [5].

Fourthly, documentation of time the procedure lasted, size of cannula used, site of insertion and any problem happened during administration. Nursing documentation is defined as anything written or printed used to furnish evidence or information that is legal or official. Effective documentation reflects the quality of care and provides evidence of each health care team members accountability in the delivery of the care. Nursing documentation comprises all written and/or computerized recording of relevant data made by nurses to document care given or to communicate information relevant to the care of the particular client/patient [7]. Nurses have always faced the challenge of recording documentation with quality patient care, some would argue that paperwork interferes with time spent caring for patients. However, with proper documentation on the patient's chart, the nurse should have the information needed to ensure quality care and to defend that care in court, and should be necessary. Effective documentation provides a record demonstration and giving proof of individualized nursing care and the patient's response to that care or outcome [8]. Nurses may consider documentation as a useful aid although it consumes time where it gives direction and ensures quality in patient care. The time and effort the nurse devotes to the patient's record allows the documentation to be pertinent, up-to-date, correct and complete. In today's litigious culture, effective and complete documentation is a matter of professional survival.

\section{Conclusions;}

1. Negligence in some activities that are dangerous and can be fatal.

2. Heedlessness in case the solution is suitable to be infused or not.

3. Heedlessness or ignorance of sterilization and disinfection.
4. Ignorance of documentation.

\section{Recommendations;}

1. The nurse must be highly qualified and efficient in regard to IV therapy.

2. Standardized guidelines in respect to sterilization and disinfection throughout each procedure.

3. Pay more attention to documentation.

\section{References;}

APP (Association of Professional Pierces), 2005, "htt://www.safepier-cing.org", Article.

Centers for Disease Control and Prevention (CDC); Hospital Infections Program "Sterilization or Disinfection of Patient-care Equipment: General Principles' http://www.cdc.gov/ncidod/diseases/hip/ Sterilgp.htm, 2008.

Dretzke, J.; Sandercock, J.; Bayliss, S. and Burls, A.; Clinical Effectiveness and Costeffectiveness of Prehospital Intravenous Fluids in Trauma Patients. Health Technol Assess, 2004; 8(23), 1-103.

Guido, W.; Scope of Practice, Legal and Ethical Issues in Nursing, $3^{\text {rd }}$ edition, New Jersey: Prentice Hall, 2001., pp.230, 258, 218.

Hanna, S.; Tibby, S.; Durward, A. and Murdoch, I.; Incidence of Hyponatraemia and Hyponatraemic Seizures in Severe Respiratory Syncytial Virus Brochiolitis. Acta Paediatr. 2003; 92(4): 430-434.

Henderson, G.; Nursing: "The importance of Documentation", Helium, 200 Brickstone Square Andover, MA. 1810, USA,2009, pp. 2-3.

Moritz, M. and Ayus, J.; Hospital Acquired Hyponatraemia - Why are Hypotonic Parenteral Fluids still being used? Nat. Clin. Pract. Nephro. 2007; 3(7): 374-82. 
Mosul Journal of Nursing, Vol. 6, No. 2, 2018 ( 89-99 )

Potter A. and Perry's C.; Fundamentals of Nursing, $2^{\text {nd }}$ edition, by Crispand taylor, 2005, pp. 307-308. 